\title{
Suicidal ideation in primary care patients suffering from panic disorder with or without agoraphobia
}

\author{
Tobias Teismann ${ }^{1 *}$, Karoline Lukaschek ${ }^{2,3}$, Thomas S. Hiller ${ }^{4}$, Jörg Breitbart ${ }^{4}$, Christian Brettschneider ${ }^{5}$, \\ Ulrike Schumacher ${ }^{6}$, Jürgen Margraf ${ }^{1}$, Jochen Gensichen ${ }^{2,4}$ and the Jena Paradies Study Group
}

\begin{abstract}
Background: Suicidal ideation is common in patients suffering from panic disorder. The present study investigated rates of suicidal ideation and risk factors for suicidal ideation in a sample of primary care patients suffering from panic disorder with or without agoraphobia.

Methods: A total of $N=296$ patients [ $n=215$ (72.6\%) women; age: $M=43.99, S D=13.44]$ were investigated. Anxiety severity, anxiety symptoms, avoidance behavior, comorbid depression diagnosis, severity of depression, age, sex, employment status, living situation and frequency of visits at the general practitioner were considered as risk factors of suicidal ideation.

Results: Suicidal ideation was experienced by $25 \%$ of the respondents. In a logistic regression analysis, depression diagnosis and depression severity emerged as significant risk factors for suicidal ideation. Anxiety measures were not associated with suicidal ideation.

Conclusion: Suicidal ideation is common in primary care patients suffering from panic disorder with or without agoraphobia. Individuals with greater burden of mental illness in terms of mood disorder comorbidity and depressive symptomatology are especially likely to suffer from suicidal ideation.
\end{abstract}

Keywords: Suicidal ideation, Panic disorder, Agoraphobia, Primary care

\section{Background}

Suicidal ideation is highly prevalent in the general population $(8.5 \%$; $[1])$ and even more in clinical samples (18-32\%; [2]). Thinking about suicide is a risk factor for completed suicide [3], and even passive ideation, such as a wish to die, has been identified as a predictor for death by suicide [4]. Since there is a rapid transition from suicidal ideation to plans and attempts [5] early detection of suicidal ideation is essential to initiate timely interventions. A better knowledge of risk factors for suicidal ideation, especially in primary care patients, may therefore help to identify potentially suicidal patients.

\footnotetext{
* Correspondence: tobias.teismann@rub.de

${ }^{1}$ Mental Health Research and Treatment Center, Ruhr-Universität Bochum,

Massenbergstraße 11, 44787 Bochum, Germany

Full list of author information is available at the end of the article
}

One of the strongest risk factors for suicidal ideation and behavior is the presence of a mental disorder, most prominently affective disorders, schizophrenia and substance use disorders [6], but also anxiety disorders [7]. Among anxiety disorders, panic disorder has received a great deal of attention: Using data from the National Institute of Mental Health Epidemiologic Catchment Area (ECA) study, Weissman et al. [8] found that $47 \%$ of individuals with panic disorder reported lifetime suicidal ideation. In European community studies lower - but still significant - rates of lifetime suicidal ideation have been found in persons suffering from panic disorder (23.7\%: [2]; 15.7\%: [9]). In studies on treatment-seeking patients suffering from panic disorder 31\% reported having had suicidal thoughts in the past year [10] and $25 \%$ in the past week [11] - even after excluding patients suffering from comorbid major depression. Taken together, there is strong evidence that patients suffering

(c) The Author(s). 2018 Open Access This article is distributed under the terms of the Creative Commons Attribution 4.0 International License (http://creativecommons.org/licenses/by/4.0/), which permits unrestricted use, distribution, and reproduction in any medium, provided you give appropriate credit to the original author(s) and the source, provide a link to the Creative Commons license, and indicate if changes were made. The Creative Commons Public Domain Dedication waiver (http://creativecommons.org/publicdomain/zero/1.0/) applies to the data made available in this article, unless otherwise stated. 
from panic disorder display heightened risk for suicidal ideation, which underscores the debilitating character of the disorder. Yet, most information concerning suicidal ideation in panic disorder stems from studies on the general population or psychiatric services [7] and may not apply to primary care settings.

The prevalence of anxiety disorders is higher in primary care settings than in the general population [12] and current panic disorder/agoraphobia diagnoses are found in about $4 \%$ of primary care patients [13]. Mental health care for panic disorder/agoraphobia is sought and obtained mostly from general practitioners [14]. Yet, suicidal ideation often goes unrecognized in these settings [15], even though almost $50 \%$ of patients who died through suicide had seen their general practitioner in the month preceding their death [16] and up to $20 \%$ visit a primary care provider within 1 day of their death [17]. In light of these findings, primary care settings have been emphasized as an essential component of effective and comprehensive suicide prevention [18].

Therefore, the first aim of this study was to identify rates of suicidal ideation in primary care patients diagnosed with panic disorder with or without agoraphobia. The second aim was to identify characteristic symptoms that are associated with suicidal ideation and may therefore guide risk assessment in primary care patients. Anxiety severity, anxiety symptoms, agoraphobic avoidance as well as depression diagnosis, depression severity, demographic markers (age, sex, living alone, unemployment) previously shown to be associated with suicidal ideation [19], and frequency of visits at the general practitioner, as an alternative measure of general distress, were considered as potential predictors of suicidal ideation.

\section{Methods}

\section{Study design}

A cross-sectional study that was nested in a randomized trial comparing a practice team-supported, selfmanaged exposure program for patients with panic disorder (PD) with or without agoraphobia (AG) in general practices to usual care was conducted [Trial Registration: ISCRTN64669297]. The study was approved by the Ethics Committee of the FriedrichSchiller-University at the Medical Faculty (Jena, Germany). Details of the study design and recruiting process have been published previously [20]. To be eligible for the trial, patients had to meet the following inclusion criteria: (1) being at least 18 years of age, (2) being diagnosed with PD/AG (ICD-10: F41.0 or F40.01) by a general practioner-led clinical interview, (3) showing a minimum total score on the 'Overall Anxiety and Impairment Scale' (OASIS) of 8 points
[21] and at least two positive answers on the panic module of the 'Patient Health Questionnaire' (PHQ; [22]) at the time of inclusion, (4) having sufficient German language skills, (5) having a telephone connection, (5) being able of giving written informed consent to participate in the study. Patients were excluded if they met one or more of the following exclusion criteria according to general practitioner's clinical evaluation: suffering from suicidal tendencies in need of immediate treatment, acute or chronic psychosis, dependence on psychoactive substance(s), or severe physical illness, being pregnant, receiving professional psychotherapeutic treatment for their anxiety disorder at the time of inclusion. Of note, none of the patients screened for the study was excluded due to suicidal tendencies in need of immediate treatment. Data collection occurred between August 2012 and October 2014.

\section{Participants}

At baseline, a sample of 419 patients took part in an exhaustive assessment. The full set of questionnaires was completed by 296 patients [ $n=215(72.6 \%)$ women; age: $M=43.99, S D=13.44$ ] and only patients who completed all questionnaires were included in the current analysis. Patients with complete data and patients who completed only a subset of questionnaires did neither differ in sex nor diagnosis. However, patients who completed only a subset of questionnaires were older than patients with complete data, $t(414)=5.23, p<.000$.

Half of the patients were married ( $n=150 ; 50.6 \%)$, $33.4 \%$ were singles $(n=99), 11.8 \%$ were separated/divorced $(n=35)$ and $4.1 \%$ were widowed $(n=12)$. A minority of patients was unemployed $(n=41,13.6 \%)$. The vast majority $(n=231,78 \%)$ suffered from panic disorder with agoraphobia, and $n=65$ (22\%) from panic disorder without agoraphobia. Fifty-five individuals (18.6\%) suffered from a comorbid depressive disorder. Most patients saw their general practitioner on a very regular basis, with $M=8.76(S D=8.72)$ visits within the last 6 months. All participants were Caucasian.

\section{Measures \\ Suicidal ideation}

Suicidal ideation was measured using the respective item from the Patient Health Questionnaire' (PHQ-9; [22]): "Over the last two weeks, how often have you been bothered by thoughts that you would be better of dead, or of hurting yourself in some way?" Response options range from "not at all", "several days", "more than half the days" to "nearly every day". Response to the PHQ-9-suicide item has recently been shown to be a strong predictor of suicide attempt and suicide death within the following year [23]. 


\section{Anxiety symptoms}

Anxiety Symptoms were measured with the Beck Anxiety Inventory (BAI; [24]). The BAI is a 21-item self-report measure that surveys anxiety symptoms on a 4-point severity scale. It has demonstrated good internal consistency (Cronbach's $\alpha \geq .85$ across clinical and non-clinical samples [25]). The internal consistency for the BAI in the current sample was $\alpha=.91$.

\section{Anxiety severity}

The Overall Anxiety Severity and Impairment Scale (OASIS; [26]) is a 5-item self-report measure to assess frequency and intensity of anxiety symptoms, functional impairment related to these symptoms and behavioral avoidance. All items are answered on a 5-point scale ranging from 0 (not at all) to 4 (extreme). The OASIS has a unidimensional factor structure and has been shown to have a good internal consistency (Cronbach's $\alpha=.89$ ) as well as convergent and divergent validity [21]. Internal consistency was rather modest in the current sample: $\alpha=.67$.

\section{Agoraphobic avoidance}

The 'Mobility Inventory' (MI; subscale 'alone'; [27]) was used to assess agoraphobic avoidance behavior across a variety of different situations. All items are answered on a 5 -point scale ranging from 1 (never) to 5 (always). The MI-total score has an excellent internal consistency: Cronbach's $\alpha \geq .94$ [27]. Accordingly, internal consistency was good in the present sample: $\alpha=.95$.

\section{Depressive symptoms}

Severity of depressive symptoms was measured by the 'Patient Health Questionnaire' (PHQ-[9, 22]). The PHQ9 assesses the occurrence of nine depressive symptoms within the previous 2 weeks. It has been shown to have good internal consistency: Cronbach's $\alpha \geq .86$ [28]. Internal consistency was $\alpha=.84$ in the present sample. The suicide item was excluded from the PHQ-sum score to avoid overlapping and thus part-whole correlations.

\section{Statistical analyses}

We conducted bivariate correlation analyses (Spearman) of all study variables. Then, a logistic regression analysis was performed with suicidal ideation (yes/no) as criterion. Age, sex, current unemployment (yes/no), living status (living alone: yes/no), frequency of visits at the general practitioner, diagnosis of panic disorder with vs. without agoraphobia, comorbid depression disorder (yes/no), depressive symptom severity, anxious symptoms, anxiety severity and avoidance behavior were considered as predictors of suicidal ideation. Derived odds rations (including 95\% confidence interval, CI) are presented for each predictor variable.
Tolerance in the collinearity statistics was higher than 0.2 for all models, indicating the absence of multicollinearity. All statistical analyses were conducted using the statistical analysis program IBM SPSS Statistics 21 (SPSS Inc., Illinois, Chicago).

\section{Results}

\section{Descriptive statistics and correlations}

Descriptive statistics for each measure are presented in Table 1 . A quarter of the sample $(25 \% ; n=74)$ reported suicidal ideation (i.e., scores $>0$ on the PHQ-9 suicide item) within the last 2 weeks: Sixty-one patients (20.5\%) indicated suffering from suicidal ideation for "several days" during the last 2 weeks, nine patients (3.1\%) indicated that they had suffered from suicidal ideation for "more than half the days" and four patients (1.4\%) indicated suffering from suicidal ideation "nearly every day".

As shown in Table 1, suicidal ideation correlates positively with anxiety symptoms, anxiety severity and depression. However, an association with avoidance behavior was not detected.

\section{Risk factors of suicidal ideation}

Table 2 shows the results of the logistic regression analysis with suicidal ideation as criterion variable.

Only comorbid depression disorder and depression severity predicted concurrent suicidal ideation. Neither anxiety symptoms nor anxiety severity and avoidance behavior emerged as significant predictors.

\section{Discussion}

Results of the present study indicate that suicidal ideation is common in primary care patients suffering from panic disorder with or without agoraphobia. In total, $25 \%$ of the patients reported suicidal ideation within the last 2 weeks. This percentage closely approximates those from other studies on patient samples suffering from anxiety disorders [11, 29] and points to the debilitating character of the disorder. In a logistic regression analysis, only comorbid depression diagnosis and depression severity emerged as significant predictors of suicidal

Table 1 Means, standard deviations and correlations of study variables

\begin{tabular}{lll}
\hline & $M(S D)$ & PHQ-SI \\
\hline PHQ-SI & $0.31(0.59)$ & - \\
BAI & $28.71(12.33)$ & $.233^{* *}$ \\
OASIS & $12.54(2.66)$ & $.190^{* *}$ \\
MI & $2.28(0.83)$ & .077 \\
PHQ & $11.10(5.25)$ & $.417^{* *}$ \\
\hline
\end{tabular}

$B A I$ Beck Anxiety Inventory, MI Mobility Inventory, OASIS Overall Anxiety Severity and Impairment Scale, PHQ Patient Health Questionaire, $P H Q-S I$ Patient Health Questionaire - Suicide Ideation Item

${ }^{* *}=p<.01$ 
Table 2 Logistic regression analysis predicting suicidal ideation

\begin{tabular}{lll}
\hline & OR $(95 \% \mathrm{Cl})$ & $21 p$ \\
\hline Age & $1.01(.99-1.04)$ & n.s. \\
Sex & $.83(.40-1.72)$ & n.s. \\
Living alone (yes/no) & $1.20(.64-2.61)$ & n.s. \\
Unemployment (yes/no) & $.79(.32-1.96)$ & n.s. \\
GP-visits & $1.02(.99-1.06)$ & n.s. \\
PD with AG vs. PD without AG & $1.07(.49-2.35)$ & n.s. \\
Comorbid depression (yes/no) & $2.33(1.12-4.84)$ & .023 \\
PHQ & $1.22(1.13-1.32)$ & .000 \\
BAl & $1.01(.98-1.04)$ & n.s. \\
OASIS & $1.02(.90-1.16)$ & n.s. \\
MI & $.70(.45-1.07)$ & n.s. \\
\hline AG Agoraphia BA Beck Anxiety Invis
\end{tabular}

AG Agoraphobia, BAI Beck Anxiety Inventory, MI Mobility Inventory, GP general practitioner, OASIS Overall Anxiety Severity and Impairment Scale, $P D$ Panic disorder, PHQ Patient Health Questionaire

ideation. Anxiety measures were not associated with suicidal ideation. Furthermore, patients suffering from panic disorder with agoraphobia were not more likely to suffer from suicidal ideation than patients suffering from panic disorder without agoraphobia.

Taken together, the current findings complement previous research that found depression to be the key risk factor for suicidal ideation and behavior within samples of anxiety patients (e.g., $[29,30])$. However, the relationship between panic disorder and suicidal ideation and behavior remains a controversial one, as some studies found such an association, even in the absence of coexisting major depression [8]. Furthermore, panic attacks have repeatedly been shown to be associated with imminent suicide risk $[31,32]$. Against this background the findings of Yaseen et al. [32] are of particular interest: they report that only fear of dying within a panic attack is prospectively associated with suicide attempts, whereas no other panic attack symptom was associated with subsequent suicidal ideation and behavior.

In terms of clinical implications, the results of the current study highlight the importance of suicide risk assessments in anxiety patients. Though suicide assessments for individuals suffering from depression has received considerable attention within primary care (e.g., [33]), findings point to the additional need for routine suicide risk assessments in patients suffering from panic disorder [29]. Taken together, general practitioners should be encouraged to ask about suicidal ideation in their anxiety patients, particularly in those suffering from comorbid depression.

The strengths of the present investigation are its embedding within the framework of the thoroughly designed Jena-PARADIES study and the use of wellestablished depression and anxiety instruments. Yet, there are some limitations to the current study. First, the present investigation is a cross-sectional analysis; therefore, conclusions on causality cannot be drawn. Second, suicidal ideation was assessed using a single item self-report measure, instead of a multi-item self-report questionnaire. Single-item assessment are associated with an increased risk of misclassification [34]; at the same time, Simon et al. [23] reported strong evidence for the predictive ability of the PHQ suicide item [23]. Third, most patients reported that suicidal ideation would occur only occasionally. It therefore remains unclear to what extent results generalize to samples with more intensive suicidal thoughts. Finally, the group of predictors used in the study was far from exhaustive. In particular, we did not measure anxiety cognitions or anxiety sensitivity, both variables that have been associated with suicidal ideation $[32,35]$.

\section{Conclusion}

The present study showed that suicidal ideation is not uncommon in primary care patients suffering from panic disorder with or without agoraphobia. Patients particularly affected are those suffering from comorbid mood disorders and depressive symptomatology [29].

\section{Acknowledgements \\ The authors thank all GPs and patients who participated in this study. \\ Funding \\ This trial was funded by the German Federal Ministry of Education and Research (BMBF; grant-number: 01GY1146). The funding source was not involved in the interpretation of the data, in the writing of the report and in the decision to submit the article for publication.}

\section{Availability of data and materials}

The datasets used and/or analysed during the current study are available from the corresponding author and/or the senior author on reasonable request.

\section{Authors' contributions}

$\Pi T$ and $\mathrm{KL}$ wrote a first draft of the current manuscript. TSH, JM and JG were responsible for the design and conception of the study. TSH, JB, CB were responsible for the acquisition of data and US for data analysis. All authors were involved in revising the manuscript critically for important intellectual content and all authors gave final approval of the current manuscript version to be published.

Ethics approval and consent to participate

The study was approved by the Ethics Committee of the FriedrichSchiller-University at the Medical Faculty (Jena, Germany). Written informed consent was obtained from all patients before study intake.

\section{Consent for publication}

Not applicable.

\section{Competing interests}

The authors declare that they have no competing interests. All authors had financial support from BMBF for the submitted work; no financial relationships with any organisations that might have an interest in the submitted work in the previous 3 years; no other relationships or activities that could appear to have influenced the submitted work.

\section{Publisher's Note}

Springer Nature remains neutral with regard to jurisdictional claims in published maps and institutional affiliations. 


\section{Author details}

${ }^{1}$ Mental Health Research and Treatment Center, Ruhr-Universität Bochum, Massenbergstraße 11, 44787 Bochum, Germany. ${ }^{2}$ Institute of General Practice and Family Medicine, University Hospital of Ludwig-Maximilians- University Munich, Pettenkoferstr. 10, D-80336 Munich, Germany. Institute of Epidemiology, Helmholtz Zentrum München, German Research Center for Environmental Health, Ingolstädter Landstraße 1, D-85764 Neuherberg, Germany. ${ }^{4}$ Institute of General Practice and Family Medicine, Jena University Hospital, Friedrich-Schiller-Universität, Bachstr. 18, D-07743 Jena, Germany. ${ }^{5}$ Department of Health Economics and Health Services Research, Hamburg Center for Health Economics, University Medical Center Hamburg-Eppendorf, Martinistr. 52, D-20246 Hamburg, Germany. ${ }^{6}$ Centre for Clinical Studies, Jena University Hospital, Salvador-Allende-Platz 27, D-07747 Jena, Germany.

Received: 22 March 2018 Accepted: 17 September 2018 Published online: 24 September 2018

\section{References}

1. Lukaschek K, Engelhardt H, Baumert J, Ladwig KH. No correlation between rates of suicide ideation and completed suicides in Europe: analysis of 49,008 participants (55+) based on the survey of health, ageing and retirement in Europe (SHARE). Eur Psychiatry. 2015:30:874-9.

2. Bernal M, Haro JM, Bernert S, Brugha T, de Graaf R, Bruffaerts R, Lépine JP, de Girolamo G, Vilagut G, Gasquet I, Torres JV, Kovess V, Heider D, Neeleman J, Kessler R, Alonso J. Risk factors for suicidality in Europe: results from the ESEMED study. J Affect Disord. 2007;101:27-34.

3. Brown GK, Beck AT, Steer RA, Grisham JR. Risk factors for suicide in psychiatric outpatients: a 20-year prospective study. J Consult Clin Psychol. 2000;68:371-7.

4. Brown GK, Steer RA, Henriques GR, Beck AT. The internal struggle between the wish to die and the wish to live: a risk factor for suicide. Am J Psychiatry. 2005;162:1977-9.

5. Borges G, Chiu WT, Hwang I, Panchal BN, Ono Y, Sampson NA, Kessler RC, Nock MK. Prevalence, onset, and transitions among suicidal behaviors. In Nock MK, Borges G, Ono Y, editors. Suicide. Global perspectives from the WHO world mental health survey. Cambridge: Cambridge University Press; 2014. p. 65-74.

6. Turecki G, Brent DA. Suicide and suicidal behavior. Lancet. 2016;387:1227-39.

7. Kanwar A, Prokop LJ, Sim LA, Feldstein D, Wang Z, Murad MH. The association between anxiety disorders and suicidal behavior: a systematic review and meta-analysis. Depress Anxiety. 2013;30:917-29.

8. Weisman MM, Klerman GL, Markowith JS, Ouelette R, Phil N. Suicidal ideation and suicide attempts in panic disorder and attacks. N Engl J Med. 1989:321:1209-14.

9. Sareen J, Cox BJ, Afifi TO, de Graaf R, Asmundson GJG, ten Have M, Stein MB. Anxiety disorders and risk for suicidal ideation and suicide attempts. Arch Gen Psychiatry. 2005;62:1249-57.

10. Cox BJ, Direnfeld DM, Swinson RP, Norton GR. Suicidal ideation and suicide attempts in panic disorder and social phobia. Am J Psychiatry. 1994;151: 882-7.

11. Fleet RP, Dupuis G, Marchand A, Burelle D, Arsenault A, Beitman MD. Panic disorder in emergency department chest pain patients. Am J Med. 1996; 101:371-80.

12. Kroenke K, Spitzer RL, Williams JB, Monahan PO, Lowe B. Anxiety disorders in primary care: prevalence, impairment, comorbidity, and detection. Ann Intern Med. 2007:146:317-25.

13. Löwe B, Gräfe K, Zipfel S, Spitzer RL, Herrmann-Lingen C, Witte S, Herzog W. Detecting panic disorder in medical and psychosomatic outpatients: comparative validation of the hospital anxiety and depression scale, the patient health questionnaire, a screening question, and physicians' diagnosis. J Psychosom Res. 2003;55:515-9.

14. Kessler RC, Chiu WT, Jin R, Ruscio AM, Shear K, Walters EE. The epidemiology of panic attacks, panic disorder, and agoraphobia in the National Comorbidity Survey Replication. Arch Gen Psychiatry. 2006;63:415-24.

15. Vannoy SD, Robins LS. Suicide-related discussions with depressed primary care patients in the USA: gender and quality gaps. A mixed methods analysis. BMJ. 2011;1:e000198.

16. Luoma JB, Martin CE, Pearson JL. Contact with mental health and primary care providers before suicide: a review of the evidence. Am J Psychiatry. 2002;169:909-16.
17. Pirkis J, Burgess P. Suicide and recency of health care contacts: a systematic review. Br J Psychiatry. 1998;36:29-35.

18. Bryan CJ, Britton PC. Treating self-directed violence in primary care settings. In: Bryan, CJ, editor. Preventing suicide attempts. A guide to brief treatments across clinical settings. New York: Routledge; 2015. p. 141-57.

19. Nock MK, Borges G, Ono Y. Suicide. Global perspectives from the WHO world mental health survey. Cambridge: Cambridge University Press; 2014.

20. Gensichen J, Hiller TS, Breitbart J, Teismann T, Brettschneider C, Schumacher U, Piwtorak A, König HH, Hoyer H, Schneider N, Schelle M, Blank W, Thiel P, Wensing M, Margraf J. Patient activation for anxiety disorders - study protocol of a cluster randomized controlled trial in primary care [ISRCTN64669297]. Trials. 2015;15:112.

21. Norman SB, Campbell-Sills L, Hitchcock CA, Sullivan S, Rochlin A, Wilkins KC Stein MB. Psychometrics of a brief measure of anxiety to detect severity and impairment: the overall anxiety severity and impairment scale (OASIS). J Psychiatr Res. 2011;45:262-8.

22. Spitzer RL, Kroenke K, Williams JB. Validation and utility of a self-report version of PRIME-MD: the PHQ primary care study. JAMA. 1999;282:1737-44.

23. Simon GS, Rutter CM, Peterson D, Oliver M, Whiteside U, Operskalski B, Ludman EJ. Do PHQ depression questionnaires completed during outpatient visits predict subsequent suicide attempt or suicide death? Psychiatr Serv. 2013;64:1195-202.

24. Beck AT, Epstein N, Brown G, Steer RA. An inventory for measuring clinical anxiety: psychometric properties. J Consult Clin Psychol. 1988;56:893-7.

25. Margraf J, Ehlers A. Beck-Angstinventar. Göttingen: Hogrefe; 2007.

26. Norman SB, Hami-Cissell S, Means-Christensen AJ, Stein MB. Development and validation of an overall anxiety severity and impairment scale (OASIS). Depress Anxiety. 2006;23:245-9.

27. Chambless DL, Caputo GC, Jasin SE, Gracely EJ, Williams C. The mobility inventory for agoraphobia. Behav Res Ther. 1985;23:35-44.

28. Kroenke K, Spitzer RL, Williams JB. The PHQ-9 - validity of a brief depression severity measure. J Gen Intern Med. 2001;16:606-13.

29. Bomyea J, Lang AJ, Craske MG, Chavira D, Sherbourne CD, Rose RD, Golinell D, Campells-Sills L, Welch SS, Sullivan G, Bystritsky A, Roy-Byrne P, Stein MB. Suicidal ideation and risk factors in primary care patients with anxiety disorders. Psychiatry Res. 2013;30:60-5.

30. Warshaw MG, Massion AO, Peterson LG, Pratt LA, Keller MB. Suicidal behavior in patients with panic disorder: retrospective and prospective data. J Affect Disord. 1995;34:235-47.

31. Fawcett J, Scheftner MD, Fogg L, Clark DC, Young MA, Hedeker D, Dibbons R. Time-related predictors of suicide in major affective disorder. Am J Psychiatry. 1990;147:1189-94

32. Yaseen ZS, Chartrand H, Mojtabai R, Bolton J, Galynker II. Fear of dying in panic attacks predicts suicide attempts in comorbid depressive illness. Depress Anxiety. 2013;30:930-9.

33. Bruce ML, Ten Have TR, Reynolds CF, Katz II, Schulberg HC, Mulsant BH, Brown GK, McAvay GJ, Pearson JL, Alexopoulos GS. Reducing suicidal ideation and depressive symptoms in depressed older primary care patients: a randomized controlled trial. JAMA. 2004;291:1081-91.

34. Millner AJ, Lee MD, Nock MK. Single-item measurement of suicidal behaviors: validity and consequences of misclassification. PLoS One. 2015; 10(10):e0141606

35. Valentiner DP, Gutierrez PM, Blacker D. Anxiety measures and their relationship to adolescent suicidal ideation and behavior. J Anxiety Disord. 2002;16:11-32.

Ready to submit your research? Choose BMC and benefit from:

- fast, convenient online submission

- thorough peer review by experienced researchers in your field

- rapid publication on acceptance

- support for research data, including large and complex data types

- gold Open Access which fosters wider collaboration and increased citations

- maximum visibility for your research: over $100 \mathrm{M}$ website views per year

At BMC, research is always in progress.

Learn more biomedcentral.com/submissions 